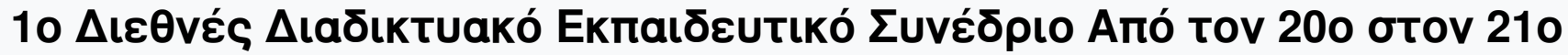

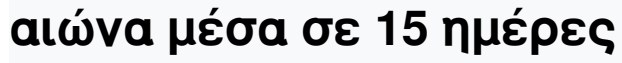

Ap. $1(2021)$

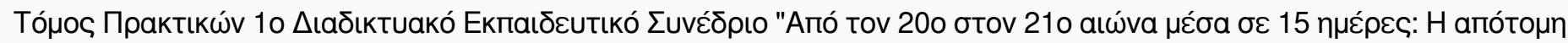

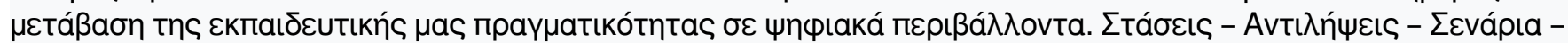

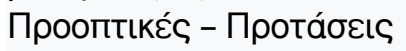

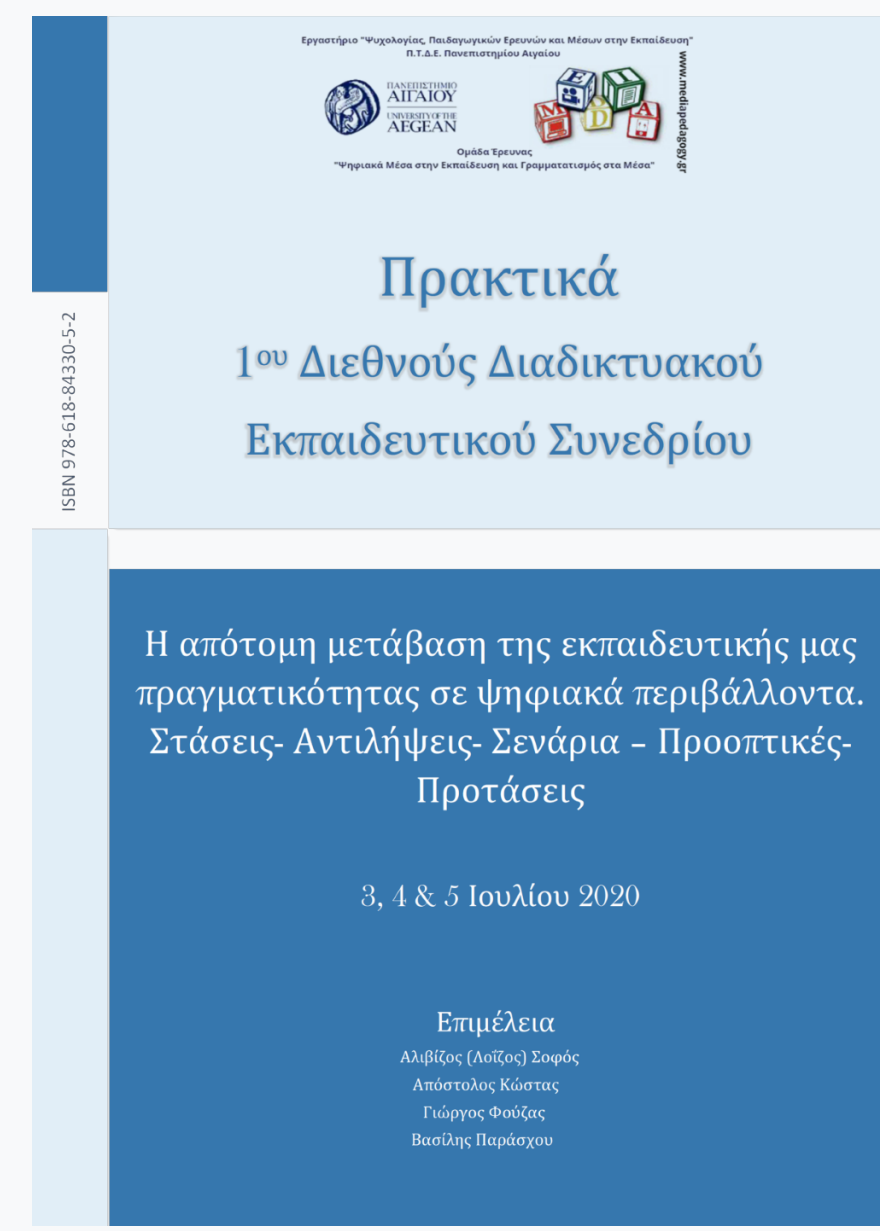

Near and far - Learning despite corona distance

Birgit Albaner, Oliver Kastner- Hauler, Karin Tengler

doi: $\underline{10.12681 / \text { online-edu.3219 }}$

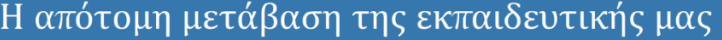

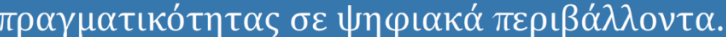

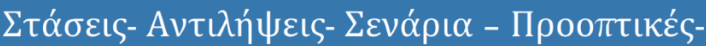

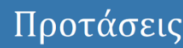

$3,4 \& 5$ Ioviíou 2020

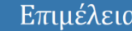

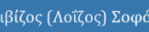

Аाँб

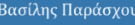




\title{
Near and far - Learning despite corona distance
}

\author{
Birgit Albaner ${ }^{1}$, Oliver Kastner- Hauler ${ }^{2}$, Karin Tengler $^{3}$ \\ birgit.albaner@ph-kaernten.ac.at, oliver.kastner@ph-noe.ac.at, k.tengler@ph-noe.ac.at \\ ${ }^{1}$ University of Education Carinthia, Media Pedagogue \\ 2 University of Education Lower Austria, IT-Expert \\ ${ }^{3}$ University of Education Lower Austria, Media Pedagogue
}

\begin{abstract}
Studying at schools and Universities of Education has changed since the beginning of March 2020. Due to requirements to contain the Covid-19 pandemic, the course of study had to be temporarily changed completely to distance learning, which demanded a high degree of adaptation and change motivation from teaching staff and students. One challenge for teachers was to provide efficient online learning with meaningful activities in such a way that the students do not lose focus on their learning goals, their motivation is kept up and communication is maintained. In order to offer schools, teachers and parents appropriate support for learning at home, during and after the corona crisis, a rich online platform was developed by lecturers of the University of Education. As an illustration, a practical adoption is shown of how to transform a course originally planned face-to-face to a blended learning version. The used combination of the elements -flipped classroom video, MOOC, recording, chat and an online portal as repository- are used for the course "Computational Thinking with a single-board computing device" will be presented. As a further initiative, a model which originates from an Erasmus+ project will be introduced. The objective of this model, the Educational Pyramid Structure, is to bring tools and methods into the education system quickly, with the greatest possible outcome and sustainability. In this context the use of Learning Flips will be displayed, which are to be produced at all levels of the school system (teacher educators, students, teachers, pupils). Centrally, this contribution will outline the overarching online platform and the results of a study conducted as part of the research project "Learning despite corona".
\end{abstract}

Keywords: Remote learning \& teaching, blended classroom

\section{Introduction}

Due to the corona pandemic, schools had to be closed in March 2020 and teachers had to take measures as quickly as possible to ensure that teaching could continue in the form of distance learning. In order to support schools, teachers and parents appropriately, in their distance teaching during and after the corona crisis, teachers at the Pedagogical University of Lower Austria and other universities developed the platform lernentrotzcorona.at, based on the model of the Pedagogical University of Schwyz (PH Schwyz, 2020). In the first phase of learning at home, the introduction of distance learning was a major topic and the optimization of practicing and deepening what had already been learned played a major role. The project "Learning despite corona" offered assistance in organization, didactics and technical implementation for learning at home.

A study of the Pedagogical University of Lower Austria (Tengler et al., 2020) was dedicated to the question of what education looked like under the conditions of the corona pandemic and what experiences with homeschooling were made in times of corona. The study examined how homeschooling worked in times of prescribed distance learning, which weaknesses, challenges and opportunities were identified and documented and whether conclusions could be drawn for the time after the corona crisis.

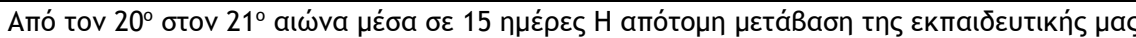

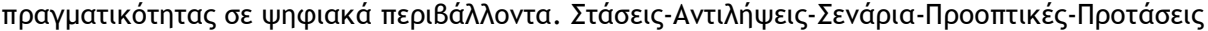




\section{Research}

The basis of the study was a comprehensive research of thematically relevant empirical studies as well as empirically based theories and models. In this case, current studies were of particular interest, since at the time of the corona pandemic distance learning was carried out under different conditions than before 2020.

An online survey was conducted via LimeSurvey. The link to the survey was shared in different social networks and platforms. Teachers, as well as parents, were contacted with the request to share it. The participation of the respondents was voluntary. The resulting sample therefore represents an ad hoc sample and is therefore not considered a random sample for the population of all interviewed groups.

Since participation in the study was voluntary and the study was mainly advertised and shared via social media and more in media-affine groups, it can be assumed that the survey was probably filled out more by people who have a positive attitude towards digital media and thus possibly also a positive attitude towards distance learning.

The results of the study (Tengler et al., 2020) include the answers of a sample of 742 persons, consisting of teachers $(n=345)$ and parents $(n=397)$. The survey was conducted in the period from the beginning of April to mid-May 2020. Of the teachers surveyed, 285 respondents $(83 \%)$ described themselves as female, 55 respondents $(16 \%)$ as male and five respondents $(1 \%)$ made no statement in this regard. In the parent survey, 347 mothers $(87 \%)$, 30 fathers $(8 \%)$ and 20 persons $(5 \%)$ who did not provide any information regarding their role answered the survey.

\section{Results}

\section{Evaluation of homeschooling}

The first question is about teachers' and parents' perceptions (Fig. 1) of how well homeschooling works in times of the corona pandemic.

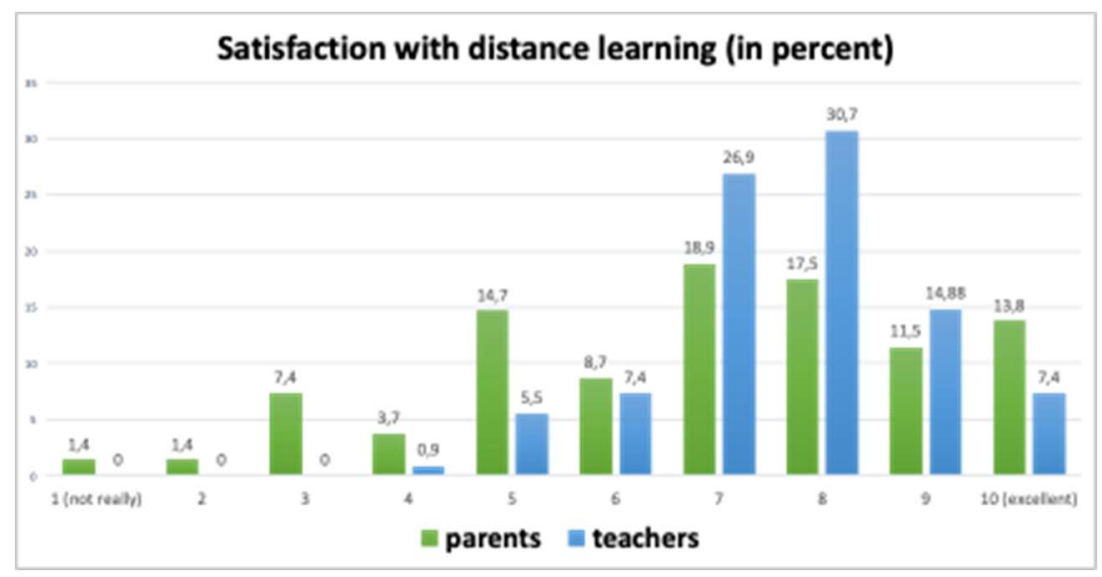

Figure 1. Satisfaction with homeschooling

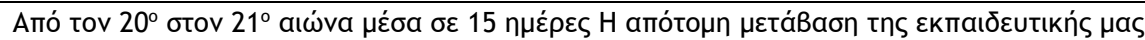

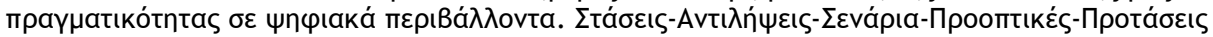




\section{Used media for distance learning}

By asking about the media used (Fig. 2), the aim was to identify the extent to which digital and analog media were used.

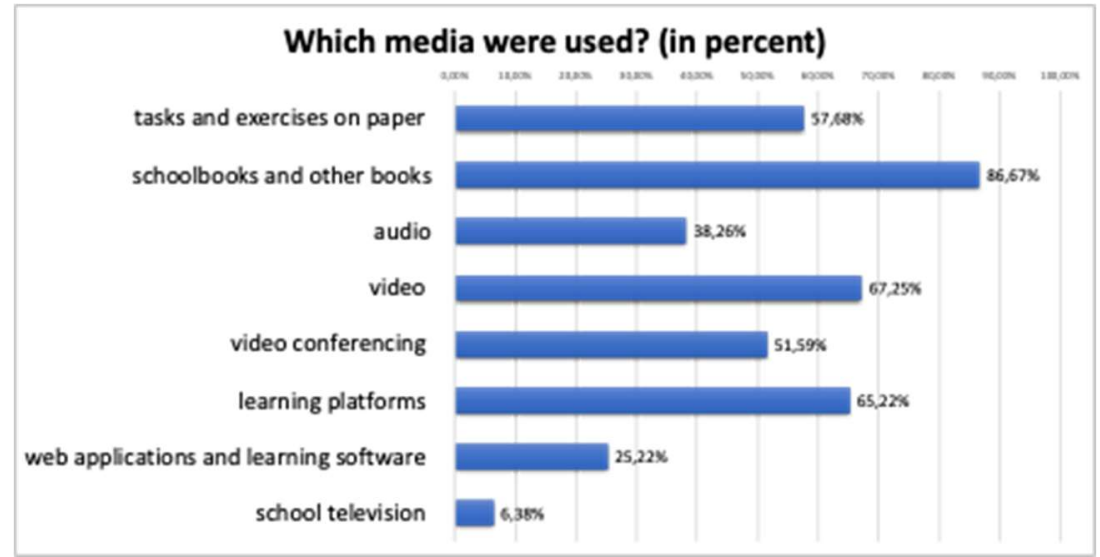

Figure 2. Used media

Both digital and analog media were used, with textbooks being the most frequently used by teachers for homeschooling (299 respondents/87.67\%). 199 respondents (57.68\%) provided the tasks and exercises to their students on paper. More than half of the teachers (178 respondents $/ 51.59 \%$ ) said they used video conferencing via Skype, MS Teams or Zoom. 232 respondents $(67.25 \%)$ also used video to convey learning content digitally. School television was used for homeschooling by only 22 teachers $(6.38 \%)$.

\section{Obstacles of distance learning}

Closed-ended questions were used to examine the possible obstacles (Fig. 3) from the parents' point of view that could influence the successful implementation of homeschooling.

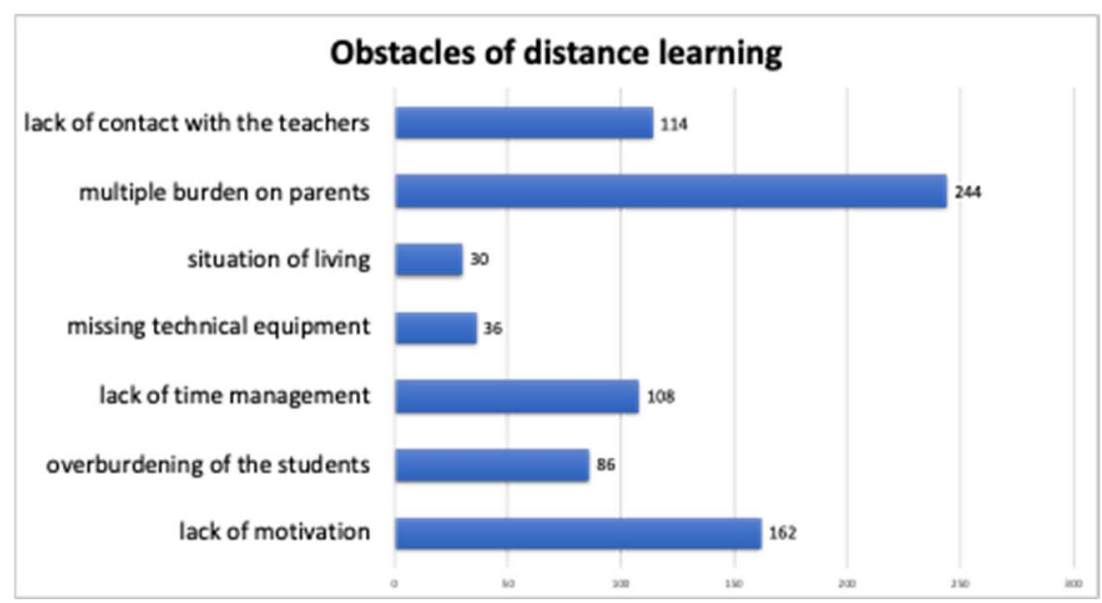

Figure 3. Obstacles of distance learning

Aпó tov $20^{\circ}$ бov $21^{\circ}$ aı

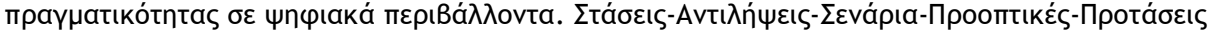


Contrary to the general opinion, parents did not see technical equipment as an obstacle to successful homeschooling - only 36 parents $(9.07 \%)$ were of this opinion. The biggest challenge for parents was clearly their additional burden (244 respondents/61.46\%). The lack of motivation of children is also an obstacle to successful homeschooling for parents (162 respondents $/ 40.81 \%)$.

\section{Conclusion and outlook}

The question about the positive experiences was formulated as open. Four aspects came up most frequently. First of all, it was clearly the independence of the children. It was formulated that the "child has become more independent and learns to organize itself". Secondly, the free allocation of time was most often mentioned as a very positive experience, because this would result in "relaxed, cooperative, happy, interested children who are allowed and able to work at their own pace", because "learning can be allocated differently" and work according to the "biorhythm". The majority of the parents felt that learning together, and the insight into the learning material and the skills of their children gained in this way, was an enormous enrichment. The fourth aspect worth mentioning was the development and promotion of digital skills and the fact that "at last we are dealing with digital tools". Another statement was: "Digital skills have been totally improved". Furthermore, no pressure to perform and the motivation on the part of the children were mentioned as positive experiences, and the extraordinary commitment of many teachers, who contribute a great deal to the successful implementation of distance learning, was emphasized.

\section{Transitioning a sample course from live teaching into distance learning}

The course titled "Programming in the classroom" with 2 ECTS2 fell into the Covid-19 pandemic phase in summer term 2020 and had to be conducted totally remotely, if possible. During this course students learn to use block-based programming and the BBC micro:bit to foster computational thinking (CT). The students are in-service teachers in lower secondary schools themselves, which desirably brings CT to their $10-14$ years old students in 5 th to 8 th grade classrooms. The course has a total workload of 50 hours (Fig. 4) including both teacher and student. The self-study of 32 hours for students remains untouched in this sample implementation.

\section{Available time for blended learning design}

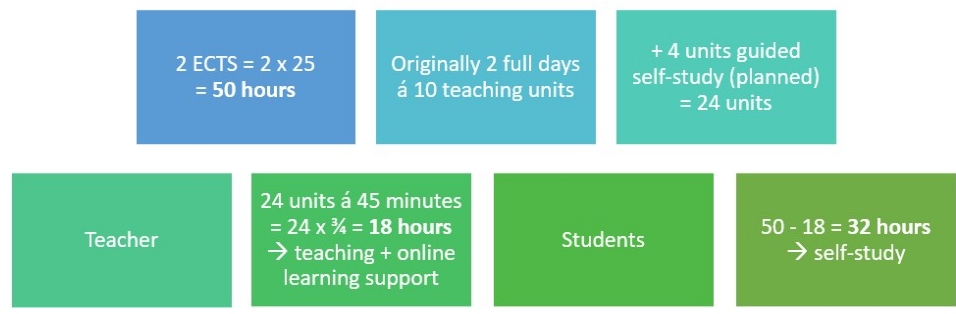

Figure 4. Total workload time layout

2 European Credit Transfer and Accumulation System (ECTS), https://en.wikipedia.org/wiki/European_Credit_Transfer_and_Accumulation_System

Aпó tov $20^{\circ}$ бtov $21^{\circ}$ aı

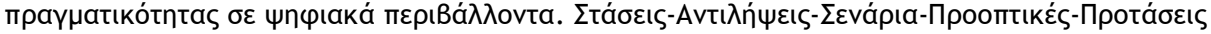


The original time frame for the "live" course is 24 units/ 18 hours - consisting of two full days of live teaching and already planned 4 units/ 3 hours of e-learning support during reflection and additional self-study (Fig. 5).

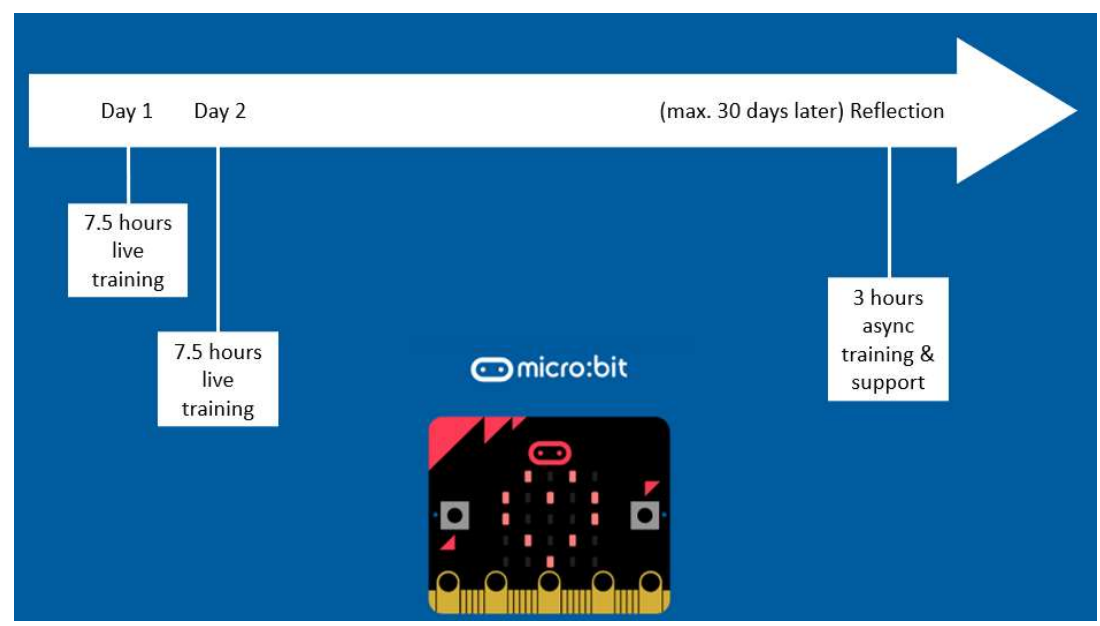

Figure 5. Original time frame "live" course

The teaching and online learning support of 18 hours was transferred into a blended version of flipped classroom, self-paced MOOC, remote synchronous sessions, and asynchronous online support using previous experience and own research in this area (Kastner-Hauler, 2020). The course started with a mandatory "Online welcome session", where the changed course layout was discussed, and students were informed what to expect from the teacher and vice-versa. At the end of this welcome session, the students received two assignments, including two videos for first introduction to the $\mathrm{BBC}$ micro:bit ${ }^{3}$ and the block-based programming environment Makecode ${ }^{4}$, to help them get started (Fig. 6, Week 1).

After the first intro, the students were given a hyperlink to a Massive Open Online Course (MOOC) $)^{5}$ on computational thinking with the BBC micro:bit where they had to earn a certificate and upload it on the learning platform for documentation (Fig. 6, Week 2-4).

Following the MOOC, one of the authors conducted two synchronous online sessions using Microsoft Teams and recorded the live stream for students not being able to follow live due to their own teaching as accorded previously (Fig. 5, Week 5/6). Each session ended with an assignment for further practice and building deeper understanding through recalling and applying what recently heard.

The final element of this course design is a longer self-study phase. To provide space for deeper reflection of what learned, a practical, hands-on output was chosen, that the students can reuse in their own teaching. The students were asked to prepare a written planning of one or more lessons and present this virtually with a short video of 2-3 minutes. In addition, each student had to provide feedback to two of his colleagues and appreciative criticize the

${ }^{3}$ BBC micro:bit single board computing device, https://microbit.org

${ }^{4}$ Microsoft Makecode web-based programming environment, https://makecode.com

5 iMooX, https://imoox.at/mooc/local/courseintro/views/startpage.php?id=54

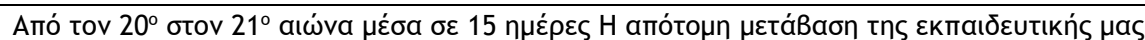

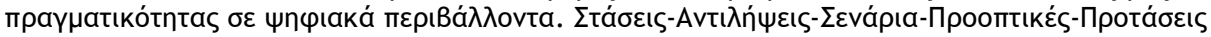


planning in an own short video. There was an open time frame of about 30 days available to upload the material to FlipGrid 6 as an example of a video platform.

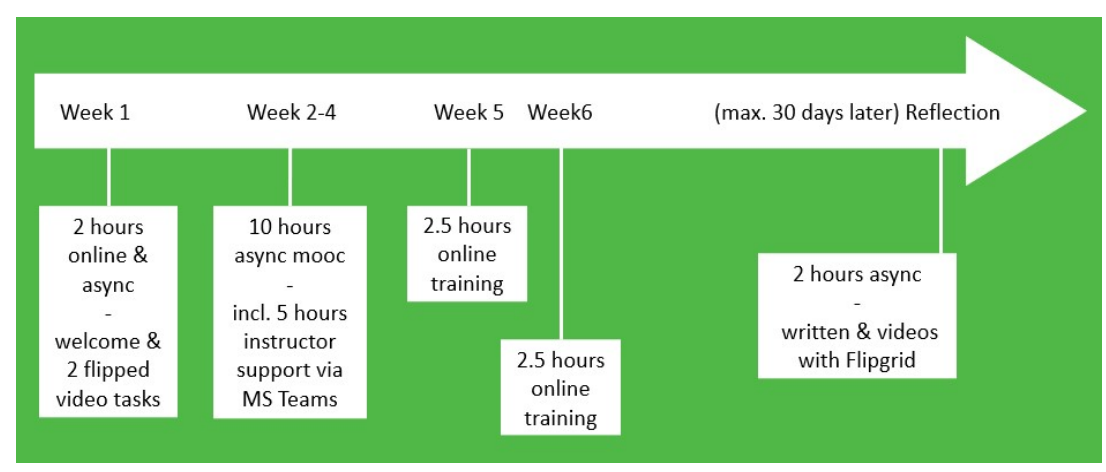

Figure 6. Adopted time frame for blended online learning

The final change of course planning (Table 1) includes a difficult to assess uncertainty regarding time needed. Therefore, an extra time of 10 hours ( 2 times 5 hours) was added as additional support buffer for the teacher trainer. This buffer was only half used during first implementation.

Table 1. Change of course planning - before/ after

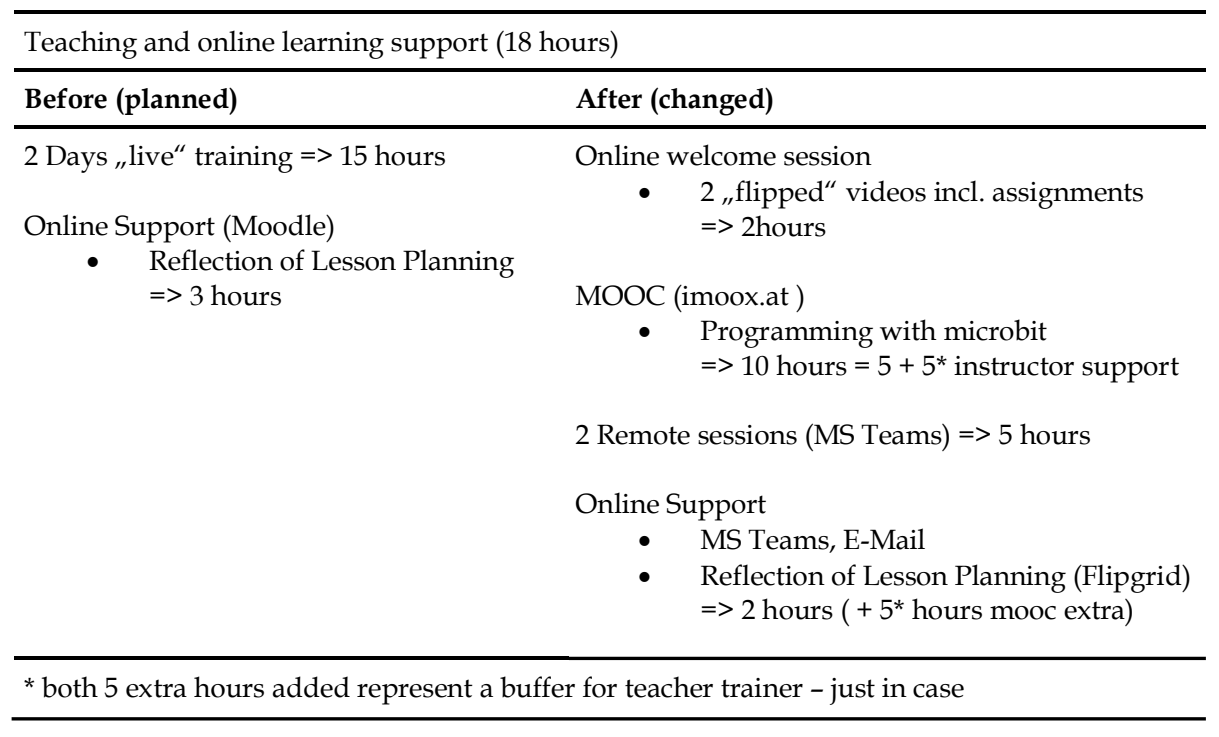

${ }^{6}$ https:// flipgrid.com

Aпó tov $20^{\circ}$ бтov $21^{\circ}$ aı

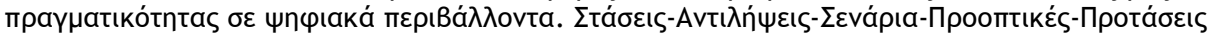




\section{New tools and didactic methods for teachers and students}

The Educational Pyramid System (Fig. 7), a new training model which represents a research assignment of a pedagogical university, involves all interest groups of the education system and therefore promises to be particularly effective and sustainable (Albaner et al., in press; Demarle-Meusel et al., 2020). The participants take on different roles and functions and should be motivated by an adapted benefit system. On the first level there are for example teacher educators, on the second students or teachers and on the third tutors are seen as students or pupils. The content that is brought into the system by this model can vary: It can be tools or methods and as an outcome for all the participants there is a focus on the production of materials, which is subsequently collected in a material pool and made available for further use.

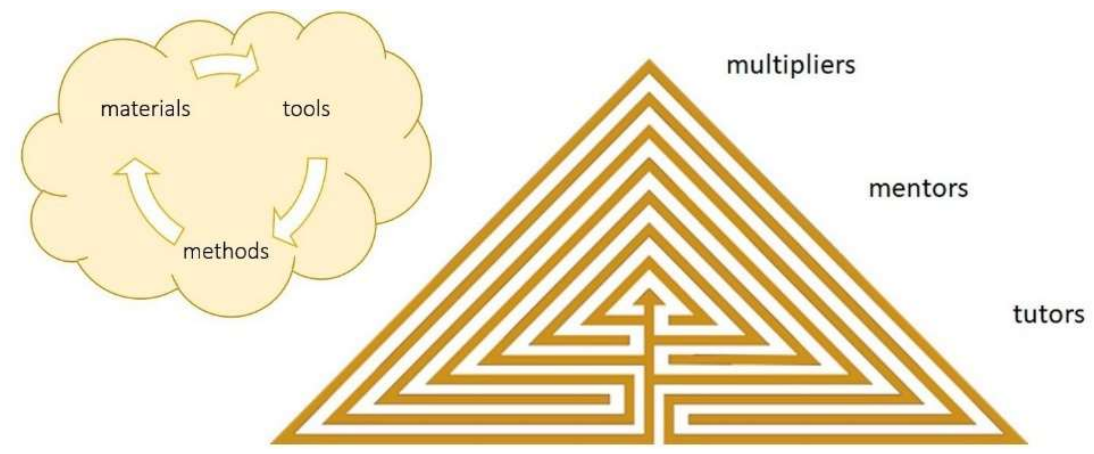

Figure 7. Model of the Educational Pyramid Structure

A new feature of this training approach is that the training involves different stakeholders who play different roles throughout the training process: Multiplier, mentor or tutor. Participants create their own materials, which is immediately implemented in the practical phase and shared with others in an online material collection. This process is accompanied by feedback, support and reflection. Continuous assistance and obligatory implementation in the own educational institution should achieve long-term effects (Darling-Hammond et al., 2017), as well as the establishment of a benefit system, which should guarantee motivation in a longterm perspective (Guskey, 2000).
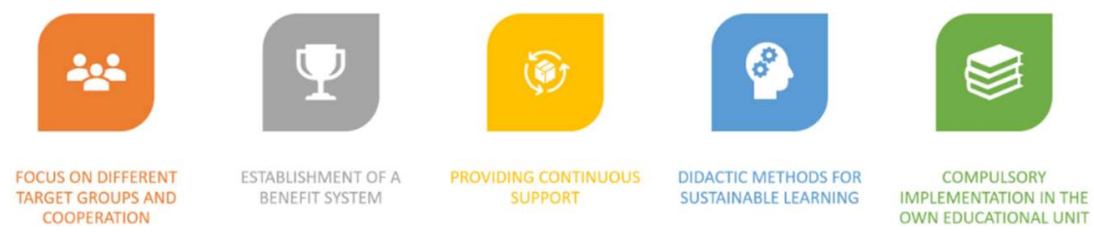

Figure 8. Main Pillars of the Educational Pyramid Structure

In a pilot phase there has been worked with Learning Flips from the Flipped Classroom Model, which were produced, practiced, evaluated and reflected on at each level. Digital tools and their use in the context of Flipped Learning were evaluated and reflected upon after a practical phase and in another face-to-face lecture (Loviscach, 2019).

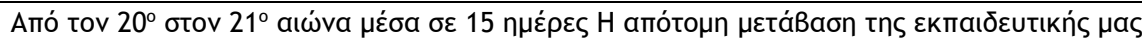

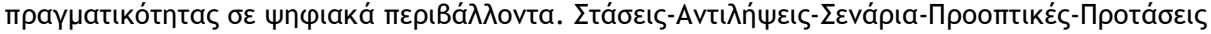


Within the framework of this pilot project, three evaluations were carried out with three groups of students of a teacher education program to assess the opportunities and challenges of the training model and the transfer of the new teaching didactics. In the first and second evaluation, focus interviews were conducted to qualitatively assess strengths and weaknesses of the model. The third survey served as a first test of a methodologically formulated competence grid and was used in an online questionnaire at the end of the qualification measure.

It presents a very interesting picture of competences in different dimensions, such as media production, media literacy, information literacy etc. and levels such as overview knowledge, practical application and transfer to others, but still needs to be thoroughly evaluated and adapted. The focus interviews after the final face-to-face session, which served as a forum for reflection and exchange of experiences, showed a clear picture: New training models work well if there is added value for all stakeholders of the system and if it can be well integrated into school life.

\section{References}

Albaner, B., Demarle-Meusel, H., Rottenhofer, M., Sabitzer, B. (n.d.). Das Educational Pyramid Scheme ein Gelingensmodell für digitale Transformation? Journal Für Schulentwicklung, 4/2020.

Darling-Hammond, L., Hyler, M. E., \& Gardner, M. (2017). Effective teacher professional development. Palo Alto, CA: Learning Policy Institute.

Demarle-Meusel, H., Rottenhofer, M., Albaner, B., \& Sabitzer, B. (2020). Educational Pyramid Scheme - A sustainable way of bringing innovation to schools. Proceedings of the 2020 Frontiers in Education International Conference.

Guskey, T. R. (2000). Evaluating professional development. Corwin press.

Kastner-Hauler, O. (2020). Making und ICM mit BBC micro:bit-Computational Thinking als "flip" eines OER-Schulbuchs. In G. Brandhofer, J. Buchner, C. Freisleben-Teutscher, K. Tengler, \& V. F. neue M. in der L. A. fnma (Eds.), Tagungsband zur Tagung Inverted Classroom and beyond 2020. Books on Demand $\mathrm{GmbH}$, Norderstedt.

Loviscach, J. (2019). Inverted Classroom Model: mehr als nur eine Vorbereitung mit Videos. In Handbuch Innovative Lehre (pp. 87-97). Springer.

PH Schwyz. (2020). Lernen trotz Corona! mia.phsz.ch. Retrieved 1 October 2020 from https://www.lernentrotzcorona.ch/Lernentrotzcorona/WebHome.

Tengler, K., Schrammel, N., \& Brandhofer, G. (2020). Lernen trotz Corona. Chancen und Herausforderungen des distance learning an österreichischen Schulen. Medienimpulse, 58(02). Retrieved 1 October 2020 from https://journals.univie.ac.at/index.php/mp/article/view/3637.

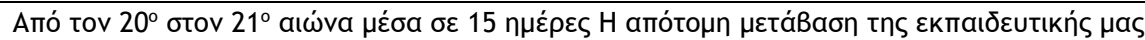

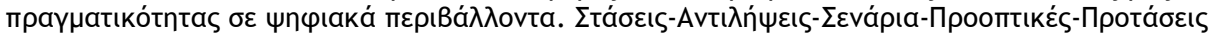

